\title{
DETERMINAÇÃO ESPECTROFOTOMÉTRICA DO ÁCIDO FOSFÓRICO POR MEIO DA REAÇÃO CERULEO-MOLÍBDICA DE DENIGÈS
}

\author{
POR

\section{Rubens Salomé Pereira}

O papel essencial que o fósforo-participador da constituição da matéria viva - desempenha na vida celular, tem determinado numerosas pesquisas orientadas no sentido da elaboração de métodos rápidos, simples, exátos, sensíveis e comodos, para a determinação quantitativa do ionio $\mathrm{PO}^{4}$. Taes processos visam sobretudo a dosagem de compostos organicos extremamente complexos, como os fosfatidos, os nucleoproteidos, etc..

Muito frequentemente são os laboratorios obrigados a fazer, em apertado espaço de tempo, grande número de determinações do fósforo em corpos extremamente pobres dêsse elemento e dos quais pouco se acha à disposição do analísta: os métodos microanalíticos são os que permitem resolver, de modo exáto e relativamente simples, as dificuldades de tal natureza.

KLEINMANN aconselha os processos gravimétricos nos casos em que a quantidade de $\mathrm{P}^{2} \mathrm{O}^{5}$ seja superior a 25 mgrs.; o método volumétrico de Neumann (1) modificado por KLeInManN (2) quando o anidrido fosfórico não se achar em quantidade inferior a 1 mgr.; a colorimetria, se o peso do $\mathrm{P}^{2} \mathrm{O}^{5}$ for superior a $0,1 \mathrm{mgr}$; e a nefelometria, quando as quantidades forem inferiores a $0,1 \mathrm{mgr}$.

SATo (3), cujo método longo e trabalhoso não encontrou acolhida na prática, precipita o acido fosfórico pelos sais de uranila e utilisa a côr que o ferrocianeto de potassio dá o precipitado obtido.

Misson (4), propõe determinar-se o fósforo pela medição da intensidade da côr que se obtem com o vanadato de amônio em presença do fósfomolibdato de amónio, devida à formação dum complexo de fórmula

$$
\mathrm{VO}^{3}\left(\mathrm{NH}^{4}\right)^{16} \text { Mo } \mathrm{O}^{2} \mathrm{PO}^{4}\left(\mathrm{NH}^{4}\right)^{3}
$$

MurRay e Ashley (5) precisaram certos pontos da técnica dêsse processo e o empregaram para a determinação espectrofotométrica do fósforo no ferro e no aço.

Os métodos colorimétricos utilisados na dosagem do acido fosfórico, baseiam-se, em geral, na produção da côr azul, graças ao emprego de redutores convenientemente escolhidos. TAYlor e Miller (6) 
recomendam os sais de hídrazina. KLEINMANN verificou não convir, a fenilhídrazina, às determinações colorimétricas, visto ela causar a turvação do soluto. Se bem que o sulfáto de hídrazina e - ainda melhor - o cloreto de hídrazina dêm bela coloração azul-marinho carregada, não se prestam bem à determinação quantitativa do acido fosfórico, visto não existir proporcionalidade entre a intensidade da côr e a quantidade de fósforo.

Buscando aplicar à dosagem do ácido fosfórico a côr vermelha produzida pelo molíbdeno em solução ácida e em presença de redutores convenientes e do rodanato de potássio, KLEINMANN (7) conclue que, embora a côr seja uma função da concentração, a relação entre essas variáveis não pode representar-se por linha réta: seria necessário traçarem-se curvas empíricas, o que daria ao método feição extremamente laboriosa e delicada. Deve-se também rejeitar o emprego do tanino e dos fenóis - ácido gálico, pirogalol, pirocatequina. Kleinmann acha que o ferrocianeto de potássio satisfaz plenamente as exigências das determinações que não envolvam quantidades inferiores a 0,1 mgr. de $\mathrm{P}^{2} \mathrm{O}^{5}$.

A dosagem do amoníaco no complexo molibdeno-fosfórico, além de ser muito trabalhósa, não oferece, pelo menos com as técnicas propostas até hoje, meio seguro para se determinar quantitativamente o ácido fosfórico.

Briggs (8) usa uma solução sulfúrica de molibdato de amônio, a hidroquinona e o sulfíto de sódio.

Fiske e SubBarow (9) recomendam dois reativos molíbdicos de acidez diferente, o sulfíto de sódio, o bisulfíto de sódio e o ácido aminonaftolsulfonico.

Von der Heide e HenNig (10) empregam a solução de azul de molibdeno preparada de acôrdo com o processo de ZiNZADZE (11), (12), (13).

Terada (14) precipita o ácido fosfórico pelo reativo estrícnomolíbdico, ajunta fenilhídrazina à solução do precipitado e obtem uma côr vermelha de vinho, que ele compara à de padrões conveniêntes. Segundo o autor, os resultados obtidos são satisfatórios no caso de as quantidades de $\mathrm{P}^{2} \mathrm{O}^{5}$ se situarem entre 0,2-0,06 mgs..

Greenhill e Pollard (15) elaboraram um processo para a determinação do fosfóro em pequenissimas quantidades de materia vegetal, obtida nas experiências feitas em vasos, e para tanto basearamse nos trabalhos de FiSKE e SUBBAROw: eles incineram a substância em presença de nitrato de magnesio e empregam o ácido sulfúrico $10 \mathrm{~N}$, o molibdato de amônio, o ácido aminonaftolsulfonico. A concentração sulfúrica final deve ser $0,5 \mathrm{~N}$; os reativos são preparados de acôrdo 
com as indicações de Warren e Pugh (16) e com as de Fiske e SubBarow : - a côr obtida é comparada à de padrões feitos a partir do fosfáto monopotássico.

ROBINSON e WIRTH (17) usam o azul de molibdeno na determinação colorimétrica do ácido fosfórico na agua. Esses investigadores acham que o método do sulfíto de hidroquinona e o do ácido aminonaftolsulfonico são satisfatórios sómente em presença de porções relativamente grandes de fósforo.

ROEPKE (18) incinera o sôro sanguineo em presença de nitrato de amônio $\ell$ de ácido nitrico, dissolve as cinzas em $2,5 \mathrm{cc}$ de ácido sulfúrico $10 \mathrm{~N}$, e em 10-20 cc de água, neutralisa a solução pelo amoníaco, passa-a para um balão de $100 \mathrm{cc}$, ajunta água até $70-80 \mathrm{cc}, 2 \mathrm{cc}$ do reativo sulfomolíbdico de Denigès, completa o volume de $100 \mathrm{cc}$ e adiciona 5 cc solução de cloreto estanoso: ao cabo de 1-2 minutos a côr se compara à de padrões no preparo dos quais se leva em consideração a quantidade de sulfáto de amônio.

Amon e Hinsberg (19) recomendam o ácido ascórbico no lugar do aminonaftolsulfonico.

URBACH (20) para dosar o fósforo total, o orgânico e o mineral, incinera a urina segundo o processo de Neumann, em tubos de experiências, e para tanto emprega 6-10 gotas de ácido sulfúrico e 1 cc de ácido nítrico. À solução diluída e neutralizada, ele ajunta molibdato de amônio a $5 \%$ em solução sulfúrica normal, hidroquinona a $2 \%$, bisulfíto de sódio a $7 \%$, e um reativo feito de súlfíto de sódio a $15 \%$ ( $500 \mathrm{cc}$ ) ajuntando a 2 litros de carbonáto de sódio a $20 \%$ - e em seguida determina a extinção dada pelo aparelho de Pulfrich.

Bomskov (2i) determina o fósforo no sangue por meio do molibdato de amônio ( 25 grs. de sal, $300 \mathrm{cc}$ de ácido sulfúrico $10 \mathrm{~N}$ e água até 1 litro) e do ácido aminonaftolsulfonico a 0,25\%. Após a côr se haver desenvolvido plenamente, ele lê a extinção dada pelo aparelho de Pulfrich.

Siwe (22) dósa o ácido fosfórico em pequenissimas quantidades de sôro $(0,05 \mathrm{cc})$ por meio do molibdato de amônio a $0,4 \%$ e duma solução de ácido aminonaftolsulfonico preparada do seguinte modo: a 0,5 gr. dêste corpo seco, ajuntam-se $195 \mathrm{cc}$ de bisulfíto de sódio a $15 \%$ e $5 \mathrm{cc}$ de sulfíto de sódio. A extinção é dada pelo aparelho de Pulfrich.

ETIENNE (23) reduz o fósfomolibdato de benzidina pelo sulfáto de hídrazina e compara a côr obtida à de padrões preparados com o ácido fósfomolíbdico tratado pelo mesmo redutor.

SteigmanN (24) usa uma solução glicerinada de gelatina e um reativo molíbdico que se prepara pelo adicionár-se a $35 \mathrm{cc}$ de ácido 
nitrico d-1,2 uma solução, feita a frio, de 5 grs. de molibdato de amônio em $100 \mathrm{cc}$ de água.

Deniaès (25) mostrou que, posto em presença do ácido molíbdico e do produto de redução dêste, o ionio $\mathrm{PO}^{4}$, observadas certas condições, fórma um composto fósfoconjugado do molibdeno, de fórmula

\section{[4 ( $\left.\left.\mathrm{Mo} \mathrm{O}^{3}\right) \mathrm{Mo} \mathrm{O}^{2}\right] \mathrm{PO}^{4} \mathrm{H}^{3}$}

que recebeu o nome de fósfoconjugado ceruleo-molíbdico. Extremamente solúvel nágua, êste corpo tinge o líquido, em cujo seio se fórma, da sua própria côr e permite a determinação quantitativa do ácido fosfórico nas mais variadas substâncias.

O meio molibdoso-molíbdico pode obter-se seja pela adição ao soluto fosfórico do reativo sulfomolíbdico de Denigès e do cloreto estanoso do mesmo autor, seja pelo ajuntar-se mistura préformada de $\mathrm{Mo} \mathrm{O}^{3}-\mathrm{Mo} \mathrm{O}^{2}$, seja ainda pelo emprego de dois reativos que se conservam separadamente: - o sulfomolíbdico diluído a $25 \%$ - reativo «A»- e o produto da redução de «A tálico - o que constitue o reativo «B».

Ao passo que o cloreto estanoso deve preparar-se no momento em que se vae empregar e que o reativo molibdoso-molíbdico mal se conserva ao cabo de uma semana, a conservação do reativo «B» é muito longa.

De acôrdo com Denigès, o ácido fosfórico, na proporção de 1 mgr. por litro, acusa-se por acentuada coloração azul, ainda perceptivel com quantidade dez vezes menor de $\mathrm{PO}^{4} \mathrm{H}^{3}$.

- Para se realizar a reação, ajuntam-se a $5 \mathrm{cc}$ da solução fosfórica, 3 gotas de «B» e 6-8 de "A», aquece-se o líquido sôbre uma chama conveniente e mantem-se a fervura durante 12 segundos, após o que se compara à de padrões a côr obtida.

- Por ser o método ceruleo-molíbdico de Denigès notavelmente sensível, cômodo, simples, rápido, exáto, e por prestar-se admirávelmente bem aos trabalhos em série, procurámos aplicá-lo à determinação espectrofotométrica do ácido fosfórico por meio do espectrofotómetro de Pulfrich.

\section{ESTUDO DAS CONDIÇÕES EXPERIMENTAIS. EXECUÇÃO DO PROCESSO ESPECTROFOTOMÉTRICO.}

Preparação dos reativos: - Empregamos os reativos «A» $\mathrm{e}$ «B» de Denigès, que preparamos do seguinte modo:

Reativo "A»: - Em um balão de $500 \mathrm{cc}$, dissolvem-se nágua fria 6,25 grs. de $\mathrm{Mo}^{7} \mathrm{O}^{24}\left(\mathrm{NH}^{4}\right)^{6}, 4 \mathrm{H}^{2} \mathrm{O}$ e completa-se o volume. Passa-se a solução assim feita para um balão de 1 litro e ajuntam-se-lhe 500 cc de ácido sulfúrico $10 \mathrm{~N}$. 
Reativo $\langle B »$ : - Num frasco amarelo ou preto, de rôlha esmerilhada, põem-se 5 grs. de raspas de cobre não oxidadas, ajuntam-se 100 cc do reativo " $\mathrm{A}$ » e deixa-se que o contáto se prolongue durante três horas, pelo menos, antes de se usar o reagente. Durante esse tempo, agita-se o frasco de vez em quando.

$\mathrm{Na}$ preparação desses reativos, usamos drogas puras, pró analise com garantia, de Merck, ou de Schering-Kahlbaum.

Modo operatório: - Usamos tubos de experiências, de vidro Pyrex, de $20 \mathrm{cms}$. de comprimento e de $20 \mathrm{mms}$. de diâmetro, graduados em $1 \mathrm{cc}-2,5 \mathrm{cc}-5 \mathrm{cc}-7,5 \mathrm{cc}-10 \mathrm{cc}$.

Põe-se quantidade exatamente medida, da solução fosfórica, num tubo, ajuntam-se os reativos $« A »$ e $« B »$ em quantidade conveniente, dilue-se com água a volume determinado, marcado na parede do tubo, arrolha-se êste com rôlha atravessada por um tubo de vidro afilado na extremidade superior e mergulha-se em banho-maria fervente até a côr apresentar o máximo de intensidade. Deixa-se a solução esfriar expontâneamente e determina-se a extinção dada pelo espectrofotómetro de Pulfrich, interpondo-se o filtro espectral S 72 e empregando-se uma cuba de capacidade eficáz apropriada. Faz-se ao mesmo tempo um branco, que serve para encher a cuba de compensação.

Influencia da reação da solução fosfórica: - A solução em que se vai determinar o ácido fosfórico, deve ser neutra ou ácida - e neste caso não deve apresentar acidez sulfúrica superior a $0,5 \mathrm{~N}$. Desde que se hajam eliminado os agentes de oxidação, a intensidade da côr se afeta a partir de certa concentração sulfúrica, o que se verifica pelo quadro seguinte:

\begin{tabular}{|c|c|c|c|}
\hline $\begin{array}{l}\mathrm{P}^{2} \mathrm{O}^{5} \\
\text { mgrs. }\end{array}$ & $\begin{array}{c}\text { Concen- } \\
\text { tracão } \\
\text { sulfurica }\end{array}$ & D & $\mathrm{k}$ \\
\hline 0,01 & - & 47,0 & 0,328 \\
\hline 0,01 & $0,1 \mathrm{~N}$ & 47,0 & 0,328 \\
\hline 0,01 & $0,2 \mathrm{~N}$ & 47,0 & 0,328 \\
\hline 0,01 & $0,3 \mathrm{~N}$ & 47,0 & 0,328 \\
\hline 0,01 & $0,4 \mathrm{~N}$ & 47,0 & 0,328 \\
\hline 0,01 & $0,5 \mathrm{~N}$ & 47,0 & 0,328 \\
\hline 0,01 & $0,6 \mathrm{~N}$ & 48,5 & 0,315 \\
\hline 0,01 & $0,7 \mathrm{~N}$ & 53,0 & 0,276 \\
\hline 0,01 & $0,8 \mathrm{~N}$ & 66,0 & 0,181 \\
\hline 0,01 & $0,9 \mathrm{~N}$ & 81,0 & 0,092 \\
\hline 0,01 & $1,0 \mathrm{~N}$ & 91,0 & 0,041 \\
\hline
\end{tabular}


A reação realizou-se com $5 \mathrm{cc}$ da solução fosfórica a que se ajuntaram os reativos $« \mathrm{~A} »-0,4 \mathrm{cc}$ e $《 \mathrm{~B} »-0,15 \mathrm{cc}$.

- Os alcalis acentuam fortemente a côr produzida na reação do ionio fosfórico, mesmo no caso de ser muito leve a alcalinidade da solução, como se vê:

\begin{tabular}{c|c|c|c}
\hline $\begin{array}{c}\mathrm{P}^{2} \mathrm{O}^{5} \\
\text { mgrs. }\end{array}$ & $\begin{array}{c}\text { Concentra- } \\
\text { çẫo alcalina } \\
\text { (Na OH) }\end{array}$ & $\mathrm{D}$ & $\mathrm{k}$ \\
\hline \hline 0,01 & - & 47,0 & 0,328 \\
0,01 & $0,01 \mathrm{~N}$ & 43,5 & 0,362 \\
0,01 & $0,02 \mathrm{~N}$ & 40,0 & 0,398 \\
0,01 & $0,03 \mathrm{~N}$ & 36,0 & 0,444 \\
0,01 & $0,04 \mathrm{~N}$ & 33,0 & 0,482 \\
0,01 & $0,05 \mathrm{~N}$ & 26,4 & 0,578 \\
\hline
\end{tabular}

Influencia do líquido de compensaçâo: - $\mathrm{O}$ reativo « $\mathrm{B}$ » comunica à solução em que se acha, certa capacidade de absorção, o que não deixa de influir sobre os resultados da dosagem, e que assim se exprime em relação à água distilada:

\begin{tabular}{|c|c|c|c|c|}
\hline \multicolumn{2}{|c|}{$\begin{array}{l}\text { Quantidade de reativos } \\
\text { em } 5 \text { cc de volume total }\end{array}$} & \multirow{2}{*}{ D } & \multirow{2}{*}{ E } & \multirow{2}{*}{ k } \\
\hline $\begin{array}{l}\text { "A" } \\
\mathrm{cc}\end{array}$ & $\begin{array}{l}\text { "B" } \\
\mathrm{cc}\end{array}$ & & & \\
\hline 0,40 & 0,00 & 100 & 0,000 & 0,000 \\
\hline 0,40 & 0,05 & 89 & 0,051 & 0,010 \\
\hline 0,40 & 0,10 & 80 & 0,097 & 0,019 \\
\hline 0,40 & 0,15 & 73 & 0,137 & 0,027 \\
\hline 0,40 & 0,20 & 64 & 0,194 & 0,039 \\
\hline 0,40 & 0,25 & 57 & 0,244 & 0,049 \\
\hline
\end{tabular}

O uso do branco em logar da água distilada, como líquido de compensação, é, pois, indispensavel, o que se confirma pelas determinações seguintes:

\begin{tabular}{c|l|c|c}
\hline $\begin{array}{c}\mathrm{P}^{9} \mathrm{O}^{5} \\
\mathrm{mgrs.} \%\end{array}$ & $\begin{array}{c}\text { Liquido de } \\
\text { compensação }\end{array}$ & $\mathrm{D}$ & $\mathrm{k}$ \\
\hline 0,2 & Agua distilada & 41,5 & 0,382 \\
0,2 & Branco & 43,5 & 0,362 \\
\hline
\end{tabular}


Poder-se-ia julgar, talvez, que conviesse empregar a água como líquido de compensação, à vista de se usarem sempre as mesmas quantidades de reativos em determinado volume final: o fáto, porém, de o produto de redução - «B» - poder, com o passar do tempo, tornar-se de mais fraco título de molibdeno reduzido, graças à oxidação expontânea, leva-nos a fazer sempre o branco.

Influencia do volume com que se executa a reação: - Si se mantiver a relação - 0,4 cc: $0,15 \mathrm{cc}$ para o volume total de $5 \mathrm{cc}-$ entre os reagentes $" A$ » $e$ " $B$ ", os resultados analíticos não se alteram pela mudança do volume final, variável dependente da concentração fosfórica da solução, como o demonstra o quadro seguinte:

\begin{tabular}{|c|c|c|c|c|c|}
\hline \multirow{2}{*}{ 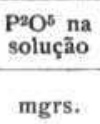 } & \multirow{2}{*}{$\begin{array}{c}\begin{array}{c}\text { Volume } \\
\text { total }\end{array} \\
\text { cc }\end{array}$} & \multicolumn{2}{|c|}{ Quantidade de reativo } & \multirow{2}{*}{ D } & \multirow{2}{*}{ k } \\
\hline & & "A" & "B" & & \\
\hline 0,01 & 2,5 & 0,20 & 0,075 & 43,5 & 0,724 \\
\hline 0,01 & 5,0 & 0,40 & 0,15 & 43,5 & 0,362 \\
\hline 0,01 & 10,0 & 0,80 & 0,30 & 43,5 & 0,181 \\
\hline
\end{tabular}

Influencia do tempo de aquecimento em banho-maria: $-\mathrm{O}$ ferverse o líquido pelo aquecimento diréto na chama do bico de Bunsen, dá, muito frequêntemente, origem a projeções que determinam a perda da analise. Preferimos fazer o aquecimento em banho-maria fervente, em que mergulhamos o tubo durante 5 minutos, pelo menos, tempo suficiente para a côr atingir o máximo de intensidade, como o demonstra o quadro seguinte:

\begin{tabular}{c|c|c|c}
\hline P2O & $\begin{array}{c}\text { Tempo de } \\
\text { aqueci. } \\
\text { mento em } \\
\text { minutos }\end{array}$ & D & k \\
\hline mgrs. \% & & \\
\hline \hline 0,40 & 1 & 37 & 0,432 \\
0,40 & 2 & 29 & 0,538 \\
0,40 & 3 & 25 & 0,602 \\
0,40 & 4 & 20 & 0,699 \\
0,40 & 5 & 19 & 0,721 \\
0,40 & 6 & 19 & 0,721 \\
0,40 & 7 & 19 & 0,721 \\
0,40 & 8 & 19 & 0,721 \\
0,40 & 9 & 19 & 0,721 \\
0,40 & 10 & 19 & 0,721 \\
\hline
\end{tabular}


A partir de 5 minutos, os resultados são constantes e inutil se torna mais prolongado aquecimento, o que, aliás, nenhum inconvêniente apresenta.

Influencia do $\mathrm{Fe}$ III: - Os sais ferricos, bem como os corpos capazes de determinar a oxidação do molibdeno reduzido, do reativo «B», impedem, quando presentes em quantidade suficiente, a produção da côr - ou, pelo menos, lhe atenuam a intensidade. E, pois, indispensavel eliminar-se essa influencia perniciosa, e para tanto o Fe III deve reduzir-se a Fe II.

Essa redução realizamô-la em tubos de experiências a que se adaptam rôlhas furadas e atravessadas por um tubo de vidro de extremidade superior afilada, e por meio de folhas delgadissimas, de alumínio, de 0,01 gr. de peso: - acidula-se a solução fosfórica, em que tambem se acha o ferro, com ácido sulfúrico titulado e exatamente medido, de sorte que a acidês, uma vez feito o volume total, não seja superior a $0,5 \mathrm{~N}$; ajunta-se uma folha de alumínio, ajusta-se a rôlha ao tubo e mergulha-se êste em banho-maria fervente. Ao cabo de 20-30 minutos, a redução acha-se, em geral, terminada e todo o alumínio metálico desaparece - fáto que bem se deve observar. Resfria-se em seguida a solução, adicionam-se-lhe os reativos « $A$ » $e$ " $B$ » e continua-se a operação como de ordinário. Faz-se um branco e emprega-se a técnica operatória descrita.

Assim procedendo, obtivémos os resultados seguintes:

\begin{tabular}{c|c|c|c}
\hline \multirow{2}{*}{$\mathrm{P}^{2} \mathrm{O}^{5}$} & Fe III & D & $k$ \\
\cline { 1 - 3 } mgrs. \% & mgrs. \% & & \\
\hline \hline 0,40 & 0,00 & 19 & 0,721 \\
0,40 & 20,00 & 19 & 0,721 \\
0,40 & 40,00 & 19 & 0,721 \\
0,40 & 50,00 & 19 & 0,721 \\
0,40 & 60,00 & 19 & 0,721 \\
\hline
\end{tabular}

Tal processo pode aplicar-se a soluções fosfóricas em que se encontrem 50 mgrs. - e mais - de Fe III em $100 \mathrm{cc}$ : os resultados obtidos são tão bons quanto os conseguidos na ausencia completa do Fe III.

Levando-se em conta a pequeníssima quantidade de substância empregada na determinação espectrofotométrica do ácido fosfórico, as probabilidades de, pelo menos nas analíses biológicas, o Fe III se apresentar em quantidade superior a 50 mgrs. \% no soluto, são excepcio- 
nais: mesmo nesses casos, podem-se obter números tão aproveitáveis como os que se conseguem na ausência dos sais ferricos.

A lei de Lambert - Beer - Determinação do coeficiente numérico: - Na determinação espectrofotométrica do ácido fosfórico por meio da reação ceruleo-molíbdica de Denigès, a lei de Lambert - Beer é perfeitamente válida, pelo menos nos limítes uteis do método. É, pois, possivel determinar-se a percentágem do ácido fosfórico duma solução, pela multiplicação dos valores da extinção por uma constante, o que, evitando a construção de curvas empíricas, fastidiósas, torna o trabalho muito mais simples e muito mais cômodo.

$\mathrm{O}$ quadro seguinte demonstra que a relação entre a concentração e o coeficiente de extinção $-\mathrm{k}-$ se traduz por uma réta, o que permite determinar-se o coeficiente numérico:

\begin{tabular}{|c|c|c|c|c|}
\hline $\mathrm{P}^{2} \mathrm{O}^{6}$ & \multirow{2}{*}{ D } & \multirow{2}{*}{ E } & \multirow{2}{*}{ k } & \\
\hline mgrs. $\%$ & & & & \\
\hline 0,01 & 81,0 & 0,092 & 0,018 & 0,555 \\
\hline 0,02 & 66,0 & 0,181 & 0,036 & 0,555 \\
\hline 0,03 & 54,0 & 0,268 & 0,054 & 0,555 \\
\hline 0,04 & 44,0 & 0,357 & 0,071 & 0,563 \\
\hline 0,05 & 36,0 & 0,446 & 0,089 & 0,562 \\
\hline 0,06 & 29,0 & 0,538 & 0,108 & 0,555 \\
\hline 0,07 & 23,0 & 0,638 & 0,128 & 0,543 \\
\hline 0,08 & 19,8 & 0,703 & 0,141 & 0,567 \\
\hline 0,09 & 15,8 & 0,801 & 0,160 & 0,562 \\
\hline 0,10 & 66,0 & - & 0,181 & 0,552 \\
\hline 0,15 & 54,0 & - & 0,268 & 0,560 \\
\hline 0,20 & 44,5 & - & 0,352 & 0,568 \\
\hline 0,25 & 35,8 & - & 0,446 & 0,560 \\
\hline 0,30 & 28,6 & - & 0,544 & 0,551 \\
\hline 0,35 & 23,4 & - & 0,631 & 0,554 \\
\hline 0,40 & 19,0 & - & 0,721 & 0,555 \\
\hline 0,45 & 15,5 & - & 0,810 & 0,555 \\
\hline 0,50 & 12,4 & - & 0,907 & 0,551 \\
\hline 0,60 & 29,0 & 0,538 & 1,076 & 0,557 \\
\hline 0,70 & 23,0 & 0,638 & 1,276 & 0,548 \\
\hline 0,80 & 19,5 & 0,710 & 1,420 & 0,563 \\
\hline 0,90 & 15,5 & 0,810 & 1,620 & 0,555 \\
\hline 1,00 & 12,4 & 0,907 & 1,814 & 0,551 \\
\hline & . & . . & . . & 0,556 \\
\hline
\end{tabular}


donde se verifica ser o êrro «standard»:

$$
\sqrt{\frac{\sum(\mathrm{d})^{2}}{\mathrm{n}(\mathrm{n}-\mathrm{I})}}=0,0013
$$

Persistencia da côr: - A côr mantem-se inalterada longo tempo após haver-se produzido - 24 horas, pelo menos - se não se encontram, na solução fosfórica, corpos oxidantes em quantidade suficiente para exercer ação descorante sôbre o fósfoconjugado e para justificar o trabalho prévio de redução, como o demonstra o quadro seguinte:

\begin{tabular}{c|c|c}
\hline $\mathrm{P}^{2} \mathrm{O}^{5}$ & $\begin{array}{c}\text { Leitura } \\
\text { feita } \\
\text { após horas }\end{array}$ & $\mathrm{k}$ \\
\hline \hline mgrs. $\%$ & \\
\hline \hline 0,5 & $1 / 4$ & 0,90 \\
0,5 & $1 / 2$ & 0,90 \\
0,5 & 1 & 0,90 \\
0,5 & 3 & 0,90 \\
0,5 & 6 & 0,90 \\
0,5 & 12 & 0,90 \\
0,5 & 24 & 0,90 \\
\hline
\end{tabular}

Si o Fe III, por ex., se achar presente em quantidado sensível, capaz de impedir o aparecimento da côr, ou de, pelo menos, the atenuar a intensidade, é necessário reduzi-lo a Fe II : a ação do oxigênio, exercendo-se então sôbre êste, no sentido de o fazer voltar ao estado férrico, determina muito mais rápida descoração do líquido, como se vê em seguida:

\begin{tabular}{c|c|c|c}
\hline $\mathrm{P}^{2} \mathrm{O}^{5}$ & Fe III & $\begin{array}{c}\text { Leitura } \\
\text { feita } \\
\text { após horas }\end{array}$ & $\mathrm{k}$ \\
\cline { 2 - 4 } mgrs. \% & mgrs. \% & $1 / 2$ & 0,90 \\
\hline \hline 0,5 & 50,0 & $1 / 4$ & 0,90 \\
0,5 & 50,0 & 1 & 0,90 \\
0,5 & 50,0 & 2 & 0,85 \\
0,5 & 50,0 & 3 & 0,65 \\
0,5 & 50,0 & 3 & \\
\hline
\end{tabular}

Reprodutividade dos resultados. Comparaf̧ão com o método volumétrico de Neumann modificado por Kleinmann: - Os resultados obtidos pelo emprego do método espectrofotométrico que propomos, 
são perfeitamente reprodutiveis e comparáveis aos oferecidos por processos bem conhecidos. Para o verificar, fizemos oito determinações espectrofotométricas do ácido fosfórico em uma só amostra de leite e comparámos os dados conseguidos com os números fornecidos pelo processo de Neumann modificado por Kleinmann:

\begin{tabular}{c|c|c|c}
\hline $\begin{array}{c}\text { Mgrs. } \\
\text { de leite }\end{array}$ & $\begin{array}{c}\text { Volume } \\
\text { final }\end{array}$ & $\mathrm{k}$ & $\begin{array}{c}\mathrm{P}^{\mathrm{P}} \mathrm{O}^{5} \\
\text { no leite } \\
\mathrm{cc}\end{array}$ \\
\hline \hline & & & \\
\hline 2,21 & 5 & 0,14 & 0,176 \\
3,32 & 5 & 0,22 & 0,184 \\
4,42 & 5 & 0,29 & 0,182 \\
5,53 & 5 & 0,37 & 0,184 \\
6,64 & 5 & 0,44 & 0,184 \\
7,75 & 5 & 0,51 & 0,183 \\
8,85 & 5 & 0,58 & 0,182 \\
10,85 & 5 & 0,72 & 0,184 \\
\multicolumn{2}{c}{ Media . . . . . . . . } & 0,182 \\
\hline
\end{tabular}

o que nos dá o êrro máximo de 0,006 e o êrro relativo de 0,033 .

Pelo processo de Neumann - Kleinmann, a percentágem de $\mathrm{P}^{2} \mathrm{O}^{5}$ achada no mesmo leite, foi de 0,179 .

\section{ALGUMAS APLICAÇÕES DO MÉTODO}

Se bem que o processo espectrofotométrico de que trata o presente trabalho, encontre aplicações muito variádas, nos exemplos que se seguem empregámo-lo apenas na determinação de várias fórmas do fósforo no plasma sanguíneo, tendo únicamente em vista a aplicação do método estudado. Essas determinações vão, pois, a título de exemplo de aplicação do processo. O estudo da extração e do isolamento das várias frações do fósforo sanguíneo, escapa inteiramente ao fim que temos em vista no momento, visto ser assunto que pretendemos estudar em trabalhos futuros.

DETERMINAÇÃO DO FÓSFORO TOTAL, DO FÓSFORO LIPÓIDICO E DO FÓSFORO ÁCIDO-SOLUVEL, NO PLASMA SANGUÍNEO.

Fósforo total: - A determinação do fósforo total compreende as duas fases seguintes:

a) - destruição da matéria orgânica;

b) - dosagem do fósforo no licor resultante do tratamento feito em (a).

a) Destruição da matéria orgânica: - Realisamo-la pelo método nitroperclórico (26), (27), da seguinte fórma: 
Num tubo de experiências, de vidro Pyrex, de $20 \mathrm{cms}$. de comprimento e de $20 \mathrm{mms}$. de diâmetro, graduado em $2,5 \mathrm{cc}-5,0 \mathrm{cc}$, introduzem-se $0,01 \mathrm{cc}-0,05 \mathrm{cc}$ de plasma e 2 cc da mistura nitroperclórica (3:1). Aquece-se em chama pequena, sob agitação constante, na capela, até o aparecimento de vapores densos, de ácido perclórico. Dada a pequenissima quantidade de substância submetida à incineração, o líquido, em geral, não se carbonisa; se, porém, tal se der, ajuntam-se algumas gotas da mistura oxidante, aguarda-se o fim da ebulição que em geral se produz então, aquece-se até secura e após até eliminação total do ácido perclórico. Após se haver resfriado o tubo, ajunta-se $1 \mathrm{cc}$ de ácido sulfúrico $0,5 \mathrm{~N}$ e aquece-se para bem se dissolverem as cinzas.

b) Dosagem do fósforo contido na solução das cinzas: - $\AA$ solução das cinzas ajuntam-se os reativos «A» $\mathrm{e}$ " $\mathrm{B}$ 》 na proporção de 0,4 cc e 0,15 cc respetivamente, para o volume total de 5 cc, completa-se o volume com água distiláda, adata-se ao tubo uma rôlha atravessada por um tubo de vidro de extremidade superior afilada e mergulhase em banho-maria fervente em que é deixado durante 5-10 minutos. Deixa-se que o resfriamento se faça expontâneamente e determina-se a extinção dada pelo aparelho de Pulfrich, interpondo-se o filtro espectral e usando-se um branco como líquido de compensação.

Assim procedendo, obtivemos os resultados seguintes:

\begin{tabular}{c|c|c|c|c|c}
\hline $\begin{array}{c}\text { Quantidade } \\
\text { de plasma }\end{array}$ & $\begin{array}{c}\text { Volume } \\
\text { total }\end{array}$ & \multirow{2}{*}{$\mathrm{E}$} & $\mathrm{k}$ & $\mathrm{P}^{2} \mathrm{O}^{5}$ & $\mathrm{P}$ \\
\cline { 1 - 5 } $\mathrm{cc}$ & $\mathrm{cc}$ & & & $\mathrm{mgrs.} \%$ & $\mathrm{mgrs.} \%$ \\
\hline \hline 0,01 & 2,5 & 0,84 & 0,168 & 23,35 & 10,21 \\
0,02 & 5,0 & - & 0,170 & 23,63 & 10,33 \\
0,04 & 5,0 & - & 0,340 & 23,63 & 10,33 \\
0,05 & 5,0 & - & 0,420 & 23,35 & 10,21 \\
\hline
\end{tabular}

Fósforo lipóidico: - Num balão de $5 \mathrm{cc}-10 \mathrm{cc}$ põem-se $1,5 \mathrm{cc}$ - 3,0 cc - 6,0 cc da mistura etéreo alcoolica ( 1 de éter: 3 de alcool a $\left.95^{\circ}\right)$ e, em seguida, $0,05 \mathrm{cc}-0,10 \mathrm{cc}-0,20 \mathrm{cc}$ de plasma, agitase o frasco e mergulha-se em banho-maria até iniciár-se a ebulição que se prolonga durante 1 minuto. Completa-se o volume do balão com quantidade suficiente da mistura dos solventes, filtra-se o líquido, afim de se separar o coágulo - e para tanto usa-se leve sucção - passa-se o filtrádo para um tubo de experiências de vidro Pyrex, graduado em 5 cc, evapora-se até secura, em banho-maria, mineraliza-se o resíduo de acôrdo com a técnica descrita anteriormente e dosa-se o fósforo como no caso do fósforo total. 
Como se vê, a extração foi feita de acôrdo com as recomendações de Bloor (28).

Por esse processo, obtivemos os numeros seguintes:

\begin{tabular}{c|c|c|c}
$\begin{array}{c}\text { Quantidade } \\
\text { de plasma }\end{array}$ & $\begin{array}{c}\text { Volume } \\
\text { total }\end{array}$ & $\mathrm{k}$ & $\mathrm{P}$ \\
\cline { 1 - 1 } $\mathrm{cc}$ & $\mathrm{cc}$ & & $\mathrm{mgrs.} \%$ \\
\hline \hline 0,05 & 5 & 0,23 & 5,59 \\
0,10 & 5 & 0,46 & 5,59 \\
0,20 & 5 & 0,91 & 5,53 \\
\hline
\end{tabular}

Fósforo ácido - solúvel: - Num tubo pequeno, de centrifugação, põem-se $0,5 \mathrm{cc}-1,0 \mathrm{cc}-2,5 \mathrm{cc}$ duma solução de ácido tricloracetico a $20 \%$ e $0,1 \mathrm{cc}-0,2 \mathrm{cc}-0,5 \mathrm{cc}$ de plasma. Após bem agitar-se o tubo, centrifuga-se energicamente e decanta-se o líquido limpido sobrenadante. Ao precipitado ajunta-se ácido tricloracetico (1 cc - $2 \mathrm{cc}$ ) agita-se a mistura e centrifuga-se bem: o líquido de lavagem adiciona-se da primeira centrifugação, posto num tubo de experiências de vidro Pyrex, graduado em 5 cc. Repetem-se as operações de lavagem: e após reunirem-se todos os líquidos no mesmo tubo graduado, evapora-se a solução até secúra, mineraliza-se o resíduo pela mistura nitroperclórica e dósa-se o fósforo de acôrdo com a técnica descrita. Assim procedendo, obtivémos os seguintes resultados:

\begin{tabular}{c|c|c|c|c}
\hline $\begin{array}{c}\text { Quantidade } \\
\text { de plasma }\end{array}$ & $\begin{array}{c}\text { Volume } \\
\text { total }\end{array}$ & $\mathrm{E}$ & $\mathrm{k}$ & $\mathrm{P}$ \\
\cline { 1 - 2 } $\mathrm{cc}$ & $\mathrm{cc}$ & & $\mathrm{mgrs.} \%$ \\
\hline \hline 0,10 & 5 & - & 0,20 & 2,43 \\
0,20 & 5 & - & 0,40 & 2,43 \\
0,50 & 5 & 0,51 & 1,02 & 2,48 \\
\hline
\end{tabular}

CALCULO DOS RESUlTADOS

Para calculár-se como $\mathrm{P}^{2} \mathrm{O}^{5}$ a percentágem de fósforo numa determinada substância, emprega-se a formula seguinte:

$$
\text { mgrs. } \% \text { de } \mathrm{P}^{2} \mathrm{O}^{5}=\frac{0,556 \times \mathrm{k} \times \mathrm{V}}{\mathrm{v}}
$$

e para determinar-se como $\mathrm{P}$, a que se segue:

$$
\text { mgrs. } \% \text { de } P=\frac{0,243, \times \mathrm{k} \times \mathrm{V}}{\mathrm{v}}
$$


em que

$\mathrm{k}=$ coeficiente de extinção;

$\mathrm{V}=$ volume total com que se realiza a reação;

$\mathbf{v}=$ volume da substância posto em analise (em cc).

No caso de ser o peso o elemento a levar-se em consideração, as formulas serão as seguintes, em que $p$ representa o peso da substância submetida à analise:

$$
\begin{gathered}
\text { mgrs. } \% \text { de } \mathrm{P}^{2} \mathrm{O}^{5}=\frac{0,556 \times \mathrm{k} \times \mathrm{V}}{\mathrm{P}} ; \\
\text { mgrs. } \% \text { de } \mathrm{P}=\frac{0,343 \times \mathrm{k} \times \mathrm{V}}{\mathrm{P}}
\end{gathered}
$$

$\mathrm{Na}$ solução em que se vai determinar o ácido fosfórico pelo método proposto - e que deve ser inicialmente incolor e limpida - não se devem encontrar corpos capazes de lhe comunicar côr própria, como os sáis de cobre, por ex., pelo menos em quantidade que permita fazer-se sentir essa ação pertubadora. No líquido fosfórico não deve haver, igualmente, corpos oxidantes, nem redutores, nem o $\mathrm{AsO}^{4}$. Este dá reação colorida como o fósforo, posto sob as mesmas condições. As observações acima ressaltam das determinações e das considerações feitas no decorrer do trabalho que ora se publíca.

\section{RESUMÉ}

Le rôle important du phosphore dans la vie cullulaire a depuis longtemps suscité les efforts des chimistes dans le but d'obtenir une methode precise de dosage de cet élément dans les composés organiques où il existe le plus souvent en très petite quantité. Après avoir passé en revue les differents procédés qui ont été successivement recommandés jusqu'ici, l'auteur expose ses propres recherches, basées sur la réaction indiquée par Denigès de l'ion phosphorique sur l'acide molybdique.

Dans certaines conditions il se forme un composé phosphoconjugué du molybdène - appelé par Denigès: phosphoconjugué céruléo-molybdique - très soluble dans l'eau à laquelle il communique une couleur bleue particulièrement avantageuse pour les dosages colorimetriques.

La comparaison de la teinte obtenue avec une gamme d'étalons déterminés permet de connaître facilement la concentration de l'ion phosphorique.

Apliquant à cette mesure le photomètre de Pulfrich, la précision de ce procédé est grandement augmentée.

Le mode opératoire auquel l'auteur s'est arrêté est be le suivant:

- On prépare les réactifs suivants: 
Réactif A - Sulfomolybdique dilué: - On dissout $6,25 \mathrm{gr}$. de $\mathrm{Mo}^{7} \mathrm{O}^{24}\left(\mathrm{~N} \mathrm{H}^{4}\right)^{6}, 4 \mathrm{H}^{2} \mathrm{O}$ dans l'eau froide et on étend à $500 \mathrm{cc}$. Aux $500 \mathrm{cc}$ de la solution on ajoute $500 \mathrm{cc}$ d'acide sulfurique $10 \mathrm{~N}$.

Réactif $B$ - Molybdeux: - On met dans un flacon jaune ou noir bouché à l'émeri, $5 \mathrm{gr}$. de tournure de cuivre non oxydée, on ajoute $100 \mathrm{cc}$ du réactif $A$, on laisse en contact pendant 3 heures aut moins en agitant de temps en temps.

La réaction s'effectue dans des tubes d'essai de verre Pyrex, de $20 \mathrm{cms}$. de longueur et $20 \mathrm{mms}$. de diamètre, graudés à $1 \mathrm{cc}-2,5 \mathrm{cc}$ $-5 c c-7,5 c c-10 c c$. On met une quantité exactement mesurée de la solution phosphorique dans le tube d'essai, on ajoute de les réactifs $A$ et $B$ en quantités convenables, on étend à un volume déterminé, on ferme avec un bouchon traversé par un tube de verre effilé à partie supérieure et l'on plonge dans un bain marie bouillant jusqu'à ce que la couleur atteigne son maximum d'intensité.

Un essai à blanc preparé avec la même technique opératoire sert comme liquide de compensation.

Dans le dosage spéctrophotométrique de l'acide phosphorique au moyen de la réaction céruléo-molybdique de Denigès, la loi de Lambert - Beer est parfaitement verifiée dans les limites utiles de la methode. Il est donc possible de déterminer la concentration de l'acide phosphorique d'une solution en multipliant les valeurs obtenues de l'extinction par un facteur constant, ce qui évite la construction de courbes d'étalonnage empiriques.

L'auteur donne ensuite les résultats qu'il a obtenu en dosant le phosphore total, le phosphore lipoidique, le phosphore acido-soluble dans le plasma sanguin.

\section{SUMMARY}

In the study of many types of biological materials, it has become of increasingly importance to stimate accurately rather small quantities of phosphorus. The need of such methods is necessitated frequently by tissues, portions of organs or compounds which, by nature of its occurence, can only be obtained in extremely minutes quantities. The investigator is then confronted with the problem of development of a method of estimation which is capable of accurately and easily estimating minutes quantities of phosphoric acid.

After a brief review of literature relating to colorimetric determination of phosphorus in a variety of materials, the writer esteems that the one worked out by Denigès appeared to be most worth studying with consideration of making photometric readings.

After studying the influence of some factors upon the development of the colour, such as reaction of the phosphoric solution, warming in 
boiling water bath, quantities of the reagents, volume, comparison liquid, oxydising and reducing agents, etc., the writer describes the following general procedure: follows:

Two reagents - «A» and «B» after Denigès - are prepared as

Reagent « $A$ »: - Dissolve 6,25 grams of $\mathrm{Mo}^{7} \mathrm{O}^{24}\left(\mathrm{~N} \mathrm{H}^{4}\right)^{6}$, $4 \mathrm{H}^{2} \mathrm{O}$ in cold water and make the volume up to $500 \mathrm{cc}$. Add $500 \mathrm{cc}$ of $10 \mathrm{~N}$ sulfuric acid.

Reagent «B»: - Into a 125 cc gllass-stoppered flask, yellow blak in colour, weigh 5 grams of pure, non oxydised copper turnings, add $100 \mathrm{cc}$ of "A», shake repeatedly. After 3 hours the reagent is ready for use.

The colourless phosphoric solution, neutral or of sulfuric acidity not above $0,5 \mathrm{~N}$, is exactly measured into a Pyrex test tube $20 \mathrm{cms}$. long by 20 mms. wide, gratuated at $1 c c-2,5 c c-5 c c-7,5 c c-10 c c$, the reagents $\langle A\rangle$ and $\langle B\rangle-0,40 \mathrm{cc}$ of $\langle A$ $A$ » and $0,15 \mathrm{cc}$ of $\langle B$ » for a total volume of $5 \mathrm{cc}$ - are added, the volume made up conveniently, the test tube stoppered by means of a cork with a central hole to which is fitted a slender glass tube very like a Pasteur pipette in form. After thoroughly mixed the contents, the test tube is plunged into a boiling water bath for 5-10 minutes spontaneously. A cell of convenient length, of the Pulfrich step-photometer is filled with the blue coloured liquid and the extinction measurement is made with the spectral filter $S 72$.

A blank experiment carried out simultaneously serves as comparison liquid.

The colours system follows Lambert - Beer's law, at least within the limits of the method, so that it is not necessary to draw curves or tables of values.

Copper, when present in proportion capable of impressing its own colour upon the system, as well as $\mathrm{AsO}^{4}$, oxydising and reducing agents, must all be removed. In the amounts usually present in biological materials even those interfering substances do not disturb. The results agree very closely with those given by the Neumann's procedure as modified by Kleinmann.

The colours is stable for 24 hours or more.

The chiefly advantages of the proposed procedure are: simplicity, rapidity, reagent economy, accurace consonant with that of other microchimical process, two easily made and enexpensively reagents, applicability with minor variation to a wide variety of materials.

The method can be used for the determination of $0,05 \gamma-100 \gamma P$. Details and applications are given. 


\section{BIBLIOGRAFIA}

1) - Neuman, A. - 1902, 1905 - Zeitschr. physiol. Chem. 37, 115; 43, 32.

2) - Kleinmann, H. - 1919 - Biochem. Zeitschr. 99, 95.

3) - Sato, A. - 1918 - Journ. of. Biol. Chem. 35, 473.

4) - Misson, G. - 1908 - Chem. Ztg. 32, 633.

5) - Murray, W. M. e Ashley, S. E. Q. - 1938 - Ind. and Eng. Chem. (Anal. edit.) 10, 1.

6) - Taylor e Miller - 1914 - Journ. of Biol. Chem. 17, 531.

7) - Kleinmann, H. - loc. cit.

8) - Briggs, A. P. - 1922, 1924 - Journ. of Biol. Chem. 53, 13; 59, 255.

9) - Fiske, C. H. e Subbarow, Y. - 1925 - Journ. of Biol. Chem. 66, 375.

10) - Von der Heide, C. e Hennig, K. - 1933 - Zeitschr. Unters. Lebensmit. 66, 344 .

11) - Zinzadze, R. - 1930 - Zeitschr. Pflanzenernähr. 16, 129.

12) - Zinzadze, R. - 1931 - Bull. Soc. Chim. France. 49, 872.

13) - Zinzadze, R. - 1932 - Zeitschr. Pflanzenernähr. 23, 447.

14) - Terada, Y. - 1924 - Biochem. Zeitschr. 145, 426.

15) - Greenhill, A. W. e Pollard, N. - 1935 - Journ. Soc. Chem. Ind. 54, 404.

16) - Warren, R. G. e Pugh, A. J. - 1930 - Journ. of Agric. Sci. 20, 532.

17) - Robinson, R. J. e Wirth, H. E. - 1935 - Ind. and Eng. Chem. (Anal. edit.) $7,147$.

18) - Roepke, R. R. - 1935 - Ind, and Eng. Chem. (Anal. edit.) 7, 78.

19) - Ammon, R. e Hinsberg, K. - 1936 - Hoppe Seyler's Zeitschr. physiol. Chem. 239, 207.

20) - Urbach, C. - 1931, 1931, 1934 - Biochem. Zeitschr. 239, 28; 239, 182; 268, 457.

21) - Bomskov, C. - 1932 - Hoppe Seyler's Zeitschr. physiol. Chem. 210, 67.

22) - Siwe, S. A. - 1935 - Biochem. Zeitschr. 278, 437.

23) - Etienne, H. - 1936 - Bull. Soc. Chim. Belgique. 45, 516.

24) - Steigmann, A. - 1936 - Chem. Ztg. 60, 12.

25) - Denigès, G. - Chelle, L. e Labat, A. - 1930 - Précis de Chimie Analytique 6ème edit. - Paris. - Maloine.

26) - Lematte, L., Boinot, G., Kahane, E. e Mme. Kahane - 1932 - Comp. rend. Acad. Sciences, 192, 1459.

27) - E. KAHANE - 1934 - L'action de l'acide perchlorique sur les matières organiques et ses applications à la chimie analytique - Actualités scientifiques et industrielles - 167 - Paris - Hermann \& Cie.

28) - Bloor, W. R. - 1914, 1915 - Journ. of Biol. Chem. 17, 377; 22, 133. 